\title{
Opinión
}

\section{La lógica del poder de observación popular en la medicina}

Verny E. Huertas- Franco

\section{Resumen}

La medicina moderna es producto de años de cuidadosa observación e investigación. Podemos decir que la observación popular inteligente es la precursora de la investigación científica moderna.

En este artículo se revisan las explicaciones encontradas a algunas de estas observaciones populares a lo largo de la práctica médica. A través del tiempo ciertas observaciones populares pueden ser explicadas científicamente y algunas tradiciones merecen ser observadas con detenimiento, ya que pueden ser de utilidad en la práctica diaria de la medicina.

El médico constantemente se encuentra con creencias populares para el tratamiento de padecimientos comunes, y a veces, la lógica de ellas es en verdad asombrosa. A través de los años, con satisfacción se ha encontrado la explicación científica para algunas de estas prácticas, que abarcan desde métodos físicos muy simples, hasta observaciones para tratamientos con explicaciones mucho más complejas.

Recibido: 8 de octubre de 2004

Aceptado: 8 de noviembre de 2004

\section{Métodos físicos populares}

Los métodos que se describen a continuación han sido demostrados como útiles:

* Estrangulación de verrugas, originalmente con un pelo, y ahora con un hilo, hasta que la verruga caiga días después, por necrosis por oclusión de la circulación.

* Aplicación de un tape o cinta adhesiva al orificio del tórsalo, para cortar el aire y obligar al parásito a subir y quedar pegado en el tape.

* Aplicación de presión sobre la hernia incarcerada con bolsa de hielo, aplicando el principio de que los gases al calentarse se expanden y cuando se enfrían se contraen, lográndose la reducción de la hernia.

* Uso de enemas de leche fría en los divertículos colónicos sangrantes, precursores del tan efectivo enema de bario frío que se administra en colaboración con el médico radiólogo, para tener el proceso de sangrado utilizado hoy.

Correspondencia:

Apdo. Postal: 125-1002 Paseo de los Estudiantes. E-mail: vhuertas@racsa.co.cr

ISSN 0001-6002/2005/47/2/76-77 Acta Médica Costarricense, (C2005 Colegio de Médicos y Cirujanos

\section{Observaciones}

\section{Orinar en la tierra para ver si la orina atrae las hormigas.}

Denota la presencia de glucosa en la orina y, por lo tanto, Diabetes Mellitus o glucosuria renal. Además, espuma o burbujas al filtrarse la orina en la tierra indican la presencia de "albúmina" (proteinuria). 


\section{Utilizar baños con agua de vinagre para eliminar el prurito en los niños con varicela.}

El ácido láctico cambia el $\mathrm{pH}$ de la piel y disminuye el prurito, lo cual es ahora parte de los remedios formales utilizados para el tratamiento del prurito.

\section{"Si tiene artritis, no coma carne roja"}

Con esto se disminuye el aporte de ácido araquidónico y la formación de radicales libres que inducen a la inflamación.

\section{"Si tiene problema de riñones, no coma carne roja ni huevos"}

La progresión de las enfermedades renales a insuficiencia renal terminal, en muchos casos es independiente de la causa original. La compensación de las nefronas remanentes luego de un daño inicial, lleva a un aumento de la presión capilar glomerular, hiperfiltración glomerular y alteración de la permeabilidad glomerular a las proteínas. Todo esto propicia un aumento en la cantidad filtrada de proteínas, y que una mayor cantidad de ellas sean reabsorbidas a nivel de túbulo proximal, resultando en daño inflamatorio intersticial progresivo, mientras se mantenga este proceso. La disminución de la carga proteica también disminuye la cantidad de residuos nitrogenados por excretar, lo que contribuye a disminuir también el proceso mencionado, causa de la progresión de las enfermedades renales de cualquier etiología, a insuficiencia renal terminal. El proceso se controla utilizando dietas bajas en proteínas, asociadas con medicamentos Inhibidores de la enzima convertidora de angiotesina o bloqueadores de receptores de angiotesina ${ }^{1}$.

\section{"Si tiene diarrea, tome almidón con o sin limón"}

El almidón se moviliza por el intestino delgado y llega al colon, en donde es metabolizado por bacterias colónicas, en ácidos grasos de cadena corta que facilitan la absorción de agua y sodio por parte del colon. Estos ácidos grasos son una fuente alterna de energía, aumentan la síntesis de proteínas y mejoran el empleo de oxígeno por parte de la mucosa colónica. El almidón fermentado resulta en una alta proporción de butirato, el ácido graso de cadena corta más efectivo en estimular la absorción de sodio y agua en el colon.

La habilidad del colon para absorber sodio contra gradiente electroquímica y su considerable capacidad de reserva para absorber fluidos, son determinantes en la disminución de la pérdida de líquido por diarrea.

\section{"Si tiene diarrea, tome agua de arroz con o sin canela"}

La solución hidratante basada en agua de arroz tiene más calorías que la solución a base de glucosa, es de sabor aceptable y reduce el volumen de diarrea aproximadamente en un $40 \%$. Además, acorta la duración de la diarrea en el cólera y enfermedades diarreicas de diferentes etiológicas. El mecanismo por el cual logra todo lo anterior es añadiendo más sustrato al lumen intestinal, sin aumentar la osmolalidad, aportando así moléculas de glucosa adicionales para la absorción mediada por glucosa. Por otro lado, en el colon los ácidos grasos de cadena corta ya mencionados, proveen una vía de absorción adicional, ya que los almidones del arroz no son completamente digeridos en el intestino delgado y entran al colon. El mecanismo de aumento de absorción que es me-diado por las soluciones de arroz, involucra más el intestino delgado que el colon, y por ello los efectos beneficiosos ocurren de manera más temprana, durante las primeras ocho horas. El efecto con las soluciones de almidón es más tardío, notorio hasta el segundo día ${ }^{4-7}$.

El tiempo ha dado la explicación para respetar científicamente muchos de los remedios que con frecuencia son despectivamente llamados "de brujas", y a los cuales se debería prestar atención, ya que se puede seguir aprendiendo de ellos en el futuro.

\section{Abstract}

Modern medicine is the product of years of careful observation and investigation. We can safely say that intelligent popular observation is the precursor of modern scientific investigation. In this article I review some of the explanations I have found to certain popular observations throughout my medical career. Over the years some popular observations can be explained scientifically, some of these traditions deserve to be closely watched because they can be useful in the daily practice of Medicine.

\section{Referencias}

Wasserstein AG. Changing patterns of medical practice: protein restriction for chronic renal failure. Ann Inter Med. July 1993; 119:79-85

2. Remuzzi G. Ruggenenti P, Perico N. Chronic Renal Diseases: Renoprotective benefits of renin-angiotensiv system inhibition. Ann Inter Med. April 2002; 136:604-615.

Ramakrishna BS, Venkataraman S, Srinivasan P, Dash P, Young GP, Binder HJ. Amylaseresistant starch plus oral rehydration for cholera. N Eng J Med. 2000; 342:308-313.

Gore SM, Fontaine O, Pierce NF. Impact of rice based oral rehydration solution on stool output and duration of diarrhea: meta analysis of 13 clinical trials. Br Med J. 1992; 304:287-291.

Gore SM, Fontaine O, Pierce NF. Efficacy of rice based oral rehydration. Lancet 1996; 348:193-194.

Molla AM, Ahmed SM, Greenough WB III. Rice based oral rehydration solution decreases the stool volume in acute diarrhea. Bull WHO. 1985; 163: 751-756.

Rabbani GH. Editorial: The search for better oral rehydration solution for cholera. N Eng J Med. 2000; 342: 345-347. 